\title{
4-Aminopyridine Toxicity: a Case Report and Review of the Literature
}

\author{
Andrew M. King • Nathan B. Menke • Kenneth D. Katz • \\ Anthony F. Pizon
}

Published online: 11 July 2012

(C) American College of Medical Toxicology 2012

\begin{abstract}
Introduction 4-Aminopyridine (4-AP) selectively blocks voltage-gated potassium channels, prolongs the action potential, increases calcium influx, and subsequently, enhances interneuronal and neuromuscular synaptic transmission. This medication has been studied and used in many disease processes hallmarked by poor neuronal transmission in both the central and peripheral nervous systems including: multiple sclerosis (MS), spinal cord injuries (SCI), botulism, Lambert-Eaton syndrome, and myasthenia gravis. It has also been postulated as a potential treatment of verapamil toxicity and reversal agent for anesthesia-induced neuromuscular blockade. To date, there have been limited reports of either intentional or accidental 4-AP toxicity in humans. Both a case of a patient with 4-AP toxicity and review of the literature are discussed, highlighting commonalities observed in overdose.

Case Report A 37-year-old man with progressive MS presented with diaphoresis, delirium, agitation, and choreathetoid movements after a presumed 4-AP overdose. 4-AP concentration at $6 \mathrm{~h}$ was $140 \mathrm{ng} / \mathrm{mL}$. With aggressive benzodiazepine administration and intubation, he recovered uneventfully.

Discussion The commonalities associated with 4-AP toxicity conforms to what is known about its mechanism of action combining cholinergic features including diaphoresis, altered mental status, and seizures with dopamine-related movement abnormalities including tremor, choreoathetosis, and dystonia. Management of patients poisoned by 4-AP centers around good supportive care with definitive airway management and controlling CNS hyperexcitability aggressively with
\end{abstract}

A. M. King $(\bowtie) \cdot$ N. B. Menke $\cdot$ K. D. Katz $\cdot$ A. F. Pizon

Division of Medical Toxicology, Department of Emergency

Medicine, University of Pittsburgh Medical Center,

PUH South Tower, Suite M2935,

Pittsburgh, PA 15213, USA

e-mail: kingam@upmc.edu gamma-aminobutyric acid agonist agents. Adjunctive use of dopamine antagonists for extrapyramidal effects after sedation is a treatment possibility. As 4-aminopyridine recently received Federal Drug Administration approval for the treatment of ambulation in patients with MS, physicians should be keenly aware of its presentation, mechanism of action, and management in overdose.

Keywords 4-Aminopyridine - Case report - Overdose · Toxicity

\section{Introduction}

4-Aminopyridine (4-AP) selectively blocks voltage-gated potassium channels, prolongs the action potential, increases calcium influx, and subsequently, enhances interneuronal and neuromuscular synaptic transmission. 4-AP was initially developed in the 1960's as an avicide (Avitrol ${ }^{\circledR}$ ). When consumed, 4-AP causes birds to emit distress calls secondary to involuntary diaphragmatic contractions. When used properly, it is reported to only actually kill about $1 \%$ of the animals $[1,2]$.

4-AP enhances the release of acetylcholine from nerve endings and has been shown to increase dopamine transmission in rat striatum [3-7]. Furthermore, it is frequently used as an experimental agent to induce seizures. Given its unique mechanism, 4-AP has been studied and used in many disease processes hallmarked by poor neuronal transmission. It has been employed with variable success for processes that affect the neuromuscular junction such as: Lambert-Eaton syndrome, myasthenia gravis, saxitoxin and tetrodotoxin-induced paralysis, anesthesia-induced neuromuscular blockade, and botulism [8-13].

In demyelinated neurons, 4-AP has been shown to improve both axonal conduction and synaptic transmission 
and, therefore, is of theoretical therapy for spinal cord injury (SCI) $[14,15]$. Unfortunately, research regarding its efficacy in SCI has been inconclusive. Although animal models and some early studies reported improvement in function and sensation, subsequent randomized, placebo-controlled studies have not demonstrated clinically significant benefits [16-22]. Summative interpretation of these results is difficult due to small numbers, mixed patient populations and variations in duration, dosage, and mechanism of administration. As a consequence, the Spinal Cord Injury Rehabilitation Evidence Research Team is currently unable to endorse the use of 4-AP for SCI based on available evidence [23].

In 2010, 4-AP received FDA approval to improve ambulation in patients with multiple sclerosis (MS). Multiple phase II and III trials have demonstrated improvement in both walking speed and function in about one third of patients [24]. The currently approved dosing regimen is $10 \mathrm{mg}$ by mouth twice daily. In a dose-ranging study, administration was discontinued due to adverse effects at doses greater than $25 \mathrm{mg}$; seizures occurred in two patients taking 30 and $35 \mathrm{mg}$ twice daily [25]. In therapeutic study doses, 4-AP has an estimated volume of distribution of $2.5 \mathrm{~L} / \mathrm{kg}$, a serum clearance of $0.6 \mathrm{~L} / \mathrm{h} / \mathrm{kg}$ and a terminal half-life of $3.6 \mathrm{~h}$. Protein binding is negligible [26]. There are currently no data regarding the use of enhanced or extracorporeal elimination. As expected, the extendedrelease formulation has a longer half-life (5.7-6.9 h) [27].

4-AP is mechanistically appealing as a potential treatment of calcium channel blocker poisoning. 4-AP facilitates calcium conductance by blocking potassium channels on the cytoplasmic side of the cellular membrane, causing depolarization and opening of voltage-gated calcium channels. Rodent and feline models have displayed improvement of hemodynamic outcomes with infusion doses of $2 \mathrm{mg} / \mathrm{kg}$ [28-30]. The $1 \mathrm{mg} / \mathrm{kg}$ dose did produce improvements in verapamil-poisoned dogs but not in other animals [28-31]. In a rodent model of verapamil poisoning, Graudins and Wong demonstrated that cardiac output and blood pressure improved with 4-AP alone and in combination with levosimendan. However, an additive effect of 4-AP and levosimendan on hemodynamics was not seen [32]. Nevertheless, case series demonstrating the effectiveness of 4-AP in the treatment of severe calcium channel blocker toxicity in humans have been published [33-36].

4-AP toxicity has been studied in many mammalian species and produces a usual sequence of signs and symptoms: hyperexcitability, salivation, tremors, diaphoresis, convulsions, and cardiac arrest $[37,38]$. To date, there have been limited reports of either intentional or accidental 4-AP toxicity in humans [39-48]. Both a case of a patient with 4AP toxicity and review of the literature are discussed, highlighting commonalities observed in overdose.

\section{Case Report}

A 37-year-old man with a medical history of chronic progressive MS and depression was transferred to a local emergency department (ED) after he was found by his brother naked and confused on the floor. He had pills in his mouth and scattered about his person. The brother had left the patient in his usual state of health for approximately $1 \mathrm{~h}$ prior to finding him in this condition. The patient's prescribed medications included: 4-aminopyridine, paroxetine, and fingolimod. Serum electrolytes were normal, and acetaminophen, salicylate, and ethanol levels were unmeasurable. Total creatinine phosphokinase measured $116 \mathrm{U} / \mathrm{L}$ $(<200 \mathrm{U} / \mathrm{L})$, and white blood count measured $10,100 / \mathrm{mm}^{3}$ $\left(3.8-10.3 \times 10^{3}\right)$ with $89 \%$ neutrophils. Electrocardiogram was normal except for sinus tachycardia. In the ED, the patient was administered intravenous (IV) fluids and $10 \mathrm{mg}$ IV lorazepam and then transferred to a tertiary care hospital for definitive management.

Upon arrival to the tertiary care hospital ED, initial vital signs included: blood pressure, 125/104 $\mathrm{mmHg}$; heart rate, $133 \mathrm{bpm}$; respiratory rate, 30 breaths per minute; oral temperature, $36.8{ }^{\circ} \mathrm{C}$; and room air $\mathrm{SpO}_{2}$ of $97 \%$. Physical examination revealed the patient to be agitated and delirious with slurred and incomprehensible speech. Other notable physical exam findings included: mid-range and reactive pupils, dry mucous membranes, diffuse diaphoresis, choreoathetoid movements, and tremulousness with $2+$ deep tendon reflexes in the upper extremities and $3+$ in the lower extremities without clonus. A non-contrasted brain computed tomogram was normal. A comprehensive urine drug screen by gas chromatography-mass spectrometry identified small amounts of diphenhydramine, caffeine, nicotine, and acetaminophen metabolites. While in the ED, he was placed in soft restraints, administered IV fluids and a total of $110 \mathrm{mg}$ IV diazepam and $50 \mathrm{mg}$ IV diphenhydramine (for possible dystonia) over a 2-h period with some improvement in agitation.

The patient was admitted to the intensive care unit (ICU) and, due to persistent agitation and delirium that was difficult to control despite an additional $20 \mathrm{mg}$ IV diazepam, he was endotracheally intubated and sedated with IV propofol $2 \mathrm{~h}$ after admission to the ICU. An electroencephalogram (EEG) revealed no epileptiform activity. The patient grimaced to strong tactile stimuli. He had gradual improvement of his mental status over the subsequent two hospital days (HD) and was extubated uneventfully on HD three. After extubation, the patient exhibited paranoid behavior and stated that people were "coming after me, hurting me, and taking my pills." This behavior gradually ameliorated, and the patient was transferred home in his baseline state on HD seven after psychiatric evaluation. A 4-AP level obtained approximately $6 \mathrm{~h}$ after his ingestion measured $140 \mathrm{ng} / \mathrm{mL}$ 
$(17.3-42.7 \mathrm{ng} / \mathrm{mL})$ with a subsequent concentration approximately $24 \mathrm{~h}$ later measuring $6 \mathrm{ng} / \mathrm{mL}$. Interestingly, the patient's brother later reported that since the initiation of 4AP, the patient had been exhibiting increasingly psychotic behavior.

\section{Case Report Toxicity Review}

In 1978, Spyker et al. reported one of the first cases of acute 4AP poisonings in three manufacturing employees who mistook 4-AP for Spanish fly and ingested it during a morning coffee break. The first patient developed intense diaphoresis, agitation, "convulsive-like movements", tachycardia, and three generalized tonic-clonic seizures. He was treated with intubation, ventilation, diazepam, naloxone, gastric lavage, sodium bicarbonate, and a sodium cathartic. He was discharged on HD five. The second patient was noted to have "profuse perspiration" as well as a fluctuating mental status including disorientation, combativeness, and unconsciousness. He was likewise treated with gastric lavage, activated charcoal, a sodium cathartic, fluids, and mannitol. The third employee successfully induced vomiting within $10 \mathrm{~min}$ of ingestion and had no "adverse effects" [39].

In 1979 during an outbreak of Clostridium botulinum type E from tinned Alaskan salmon, four elderly patients were treated with intravenous 4-AP. Restoration of evoked peripheral muscle action potentials and power was noted. 4AP did not, however, improve ventilatory muscle power. Interestingly, seizures were reported in two patients after discontinuation of the 4-AP infusion, and they received 60-80 mg diazepam. Serum levels in the two patients who developed seizures ranged between 30 and $475 \mathrm{ng} / \mathrm{mL}$ during the infusion. One patient with seizures and another without died of "sudden respiratory obstruction" and "bronchopneumonia and severe metabolic acidosis" [14].

Stork and Hoffman in 1994 published a case series of three patients with 4-AP overdose resulting in seizure activity. The first case described a 28 -year-old woman with MS who consumed extra 4-AP in attempts to ameliorate increased lower extremity weakness. The patient experienced two seizures and was treated with diazepam, lorazepam, phenytoin, activated charcoal, and intubation. A 4-AP concentration measured $136.3 \mathrm{ng} / \mathrm{mL}$. The second case described a 54-year-old woman who suffered two seizures after being started on an escalating dose of 4-AP (exact dose unknown). The third patient was a 52-year-old woman with MS and developed 40 min of status epilepticus. She was treated with diazepam, phenytoin, and phenobarbital. No long-term adverse outcomes were reported in any of the patients [41].

In 1995, Pickett and Enns reported the first case of extrapyramidal manifestations of 4-AP toxicity. They described a 34-year-old woman with MS who increased her dose in anticipation of extra activity during the day and developed "tremulous dystonic and choreoathetoid-type writhing of the extremities." She had a fixed stare, slurred speech, confabulation, and delirium. She was treated with lorazepam which caused a "rapid cessation of the shaking", and the involuntary movements improved over $1 \mathrm{~h}$. Vital signs included: pulse, $90 \mathrm{bpm}$; blood pressure, 129/61 $\mathrm{mmHg}$; respirations, 36 breaths/min; and oral temperature, $33.8^{\circ} \mathrm{C}$. The authors inferred that the hypothermia was likely factitiously low in the setting of tachypnea. This patient's measured concentration was $233.6 \mathrm{ng} / \mathrm{mL}$ [42].

Smeets and Kunst in 1995 described a case of accidental 4-AP intoxication of a 22-year-old man who mistakenly took the medication assuming it was a bodybuilding supplement given its name contained "amino." He was reported to have developed cardiac dysrhythmias, transient right bundle-branch block, accelerated idioventricular rhythm, and "severe" hypertension. The serum concentration was measured at $335 \mathrm{ng} / \mathrm{mL}$ [43].

The first pediatric exposure resulting in toxicity was reported by Velez et al. in 2003. The subject of their paper was an 8-month-old boy who was found with greenish saliva next to a capsule with green 4-AP powder missing. The boy was tachycardic and tachypneic and developed "dramatic opisthotonic posturing and vermiform tongue fasciculations." An EEG did not demonstrate seizure activity, and the patient fully recovered within $20 \mathrm{~h}$ [44].

In 2006, Johnson and Morgan reported a second case of cardiotoxicity in the setting of 4-AP ingestion. A 56-yearold man rubbed 4-AP on a sore tooth after he had noted the local anesthetic effects on his tongue and throat after taking it for peripheral neuropathy. He was found by his son $1 \mathrm{~h}$ after ingestion, diaphoretic, and delirious with unintelligible speech. He developed hypothermia to $32.8{ }^{\circ} \mathrm{C}$ and atrial fibrillation with rapid ventricular response. He was treated with intubation, cardioversion, and rewarming and fully recovered. The cause of both the hypothermia and atrial fibrillation remained enigmatic [45].

In 2008, Burton and colleagues described a case series of four patients who were admitted to the hospital for status epilepticus after an unintentional overdose of 4-AP secondary to a compounding error by a Canadian pharmacy. All developed symptoms within minutes to hours of ingestion. All patients were intubated and received benzodiazepines and phenytoin. One patient subsequently died from a prolonged hospital stay and "systemic complications" [46].

In 2009, De Cauwer et al. reported a third case of a patient with 4-AP toxicity associated with extrapyramidal symptoms. A 45-year-old woman ingested $35 \mathrm{mg}$ of 4-AP in three doses over $10 \mathrm{~h}$ and was found by her daughter unresponsive with a fixed stare. She was shaking and exhibited choreoathetoid movements. She was also noted 
to have slurred speech with confabulation. Unique to this case was the fact that the patient had reappearance of her symptoms almost immediately after re-initiation of 4-AP and additionally developed opisthotonus and risus sardonicus [47].

A fourth case of a patient experiencing extrapyramidal dysfunction was reported by Badruddin et al. in 2009. They described a case of a 22-year-old man with MS who ingested $300 \mathrm{mg}$ of 4-AP. He was agitated, diaphoretic, flushed, febrile hypertensive, and also experienced supraventricular tachycardia. He was intubated, and an EEG showed frequent "diffuse polyspike and spike-wave discharges." Echocardiogram demonstrated a hypokinetic myocardium with an ejection fraction of $24 \%$ that later normalized. Five days after the overdose, he was bradykinetic, weak (1/5 on the Ashworth scale), sustained "profound" memory loss, and spoke rarely and quietly. These symptoms slowly improved with therapy over a period of months; however, he continued to have difficulty with shortterm memory and learning new tasks. Magnetic resonance imaging (MRI) of the brain demonstrated increased signal intensity in both medial temporal lobes and the anterior cingulum (baseline MRI prior to overdose did not have these changes). The clinical presentation resembled autoimmunemediate limbic encephalitis [48].

Finally, in 2011, Schwam reported 4-AP toxicity attributed to a compounding error in a 42-year-old man with a C3 SCI. He was noted to have abdominal pain, profuse diaphoresis, hypersalivation, and choreoathetosis followed by status epilepticus. This unfortunate gentleman had a prolonged and complicated hospital course including sepsis, gastrointestinal bleeding, nonST segment elevation myocardial infarction and intracranial hemorrhage. He developed permanent amnesia. [49].

\section{Discussion}

A summary of cases with documented toxicity related to 4AP is shown in Table 1. There appears to be a fairly consistent constellation of signs and symptoms observed in the setting of 4-AP toxicity: diaphoresis, neurologic excitability, gastrointestinal effects, and cardiac toxicity.

Extrapyramidal movement abnormalities-ranging from bradykinesia to choreoathetosis to opisthotonus - have been independently reported. Other manifestations of neural excitability including confabulation, agitation, paresthesias, and tremor are likewise commonly described. Neurologic side effects that have been reported in study populations with variable frequency include: dizziness, ataxia, insomnia, and lightheadedness $[9,50-55]$. There have been two reports of long-term memory difficulties in patients after overdose, but no long-term effects have been reported with therapeutic use [48, 49, 52].
Seizures occur commonly with 4-AP toxicity and can progress to status epilepticus. The reported incidence of seizures with therapeutic use ranges between 1 and $3 \%$, which is comparable to the baseline incidence of seizures in patients with MS [56-58]. In clinical trials of the extendedrelease formulation of 4-AP, seizures appear to be dose related $[27,40,55]$. Seizures have been observed with 4AP concentrations ranging between 30 and $475 \mathrm{ng} / \mathrm{mL}$ [14, 41]. In contrast, 4-AP concentrations up to $114 \mathrm{ng} / \mathrm{mL}$ have been measured in study participants without serious effect while a seizure was reported in a study participant with a level of $104 \mathrm{ng} / \mathrm{mL}[59,60]$. In the same study, an "acute confusional episode" without seizure was reported at a concentration of $114 \mathrm{ng} / \mathrm{mL}$ [59]. With respect to 4-AP concentrations obtained in the setting of overdose, the timing of measured blood concentrations in relation to the ingestion is often unclear. Based on the available literature, serum 4-AP concentrations appear helpful in establishing exposure yet unreliable in accurately assessing clinical toxicity.

Various cardiac effects have been described with 4-AP toxicity and include: hypertension, supraventricular tachycardia, atrial fibrillation, bradycardia, and diffuse myocardial hypokinesis. The associated atrial fibrillation in the one patient described above is difficult to interpret as this patient was concomitantly hypothermic which may have caused myocardial irritability. There is a theoretical concern for QT prolongation through inhibition of the hERG potassium channel as 4-AP is a potassium channel blocker. Using terfenadine as a control, 4-AP was evaluated in concentrations ranging from 0.1 to $30 \mathrm{mM}$ in human embryonic kidney 293 cells transfected with the hERG gene. At three orders of magnitude higher than expected therapeutic plasma concentrations, $50 \%$ inhibition was observed. The authors concluded that at therapeutic doses, 4-AP has low potential for prolonging QT interval or inducing Torsades de pointes [61]. This mirrors reported clinical experience in both therapeutic trials and overdose. Several studies have documented a lack of effect on cardiac repolarization in both therapeutic and supratherapeutic doses [51, 62, 63]. Reports of death were not due to acute cardiotoxicity but rather acquired respiratory disease (e.g., ventilator-associated pneumonia) and complications related to a prolonged hospital course $[14,46]$.

4-AP has other miscellaneous toxicities. Gastrointestinal effects such as dry mouth, nausea, and vomiting are relatively common; elevated liver enzymes have been reported [52]. Diffuse, profound diaphoresis is common. Hematologic effects include thrombocytopenia. Posterior tibial artery vasospasm was discussed in one case and was successfully treated with oral nifedipine [20].

Seizure activity was not observed or documented in the patient described in this manuscript. Taking into account the 


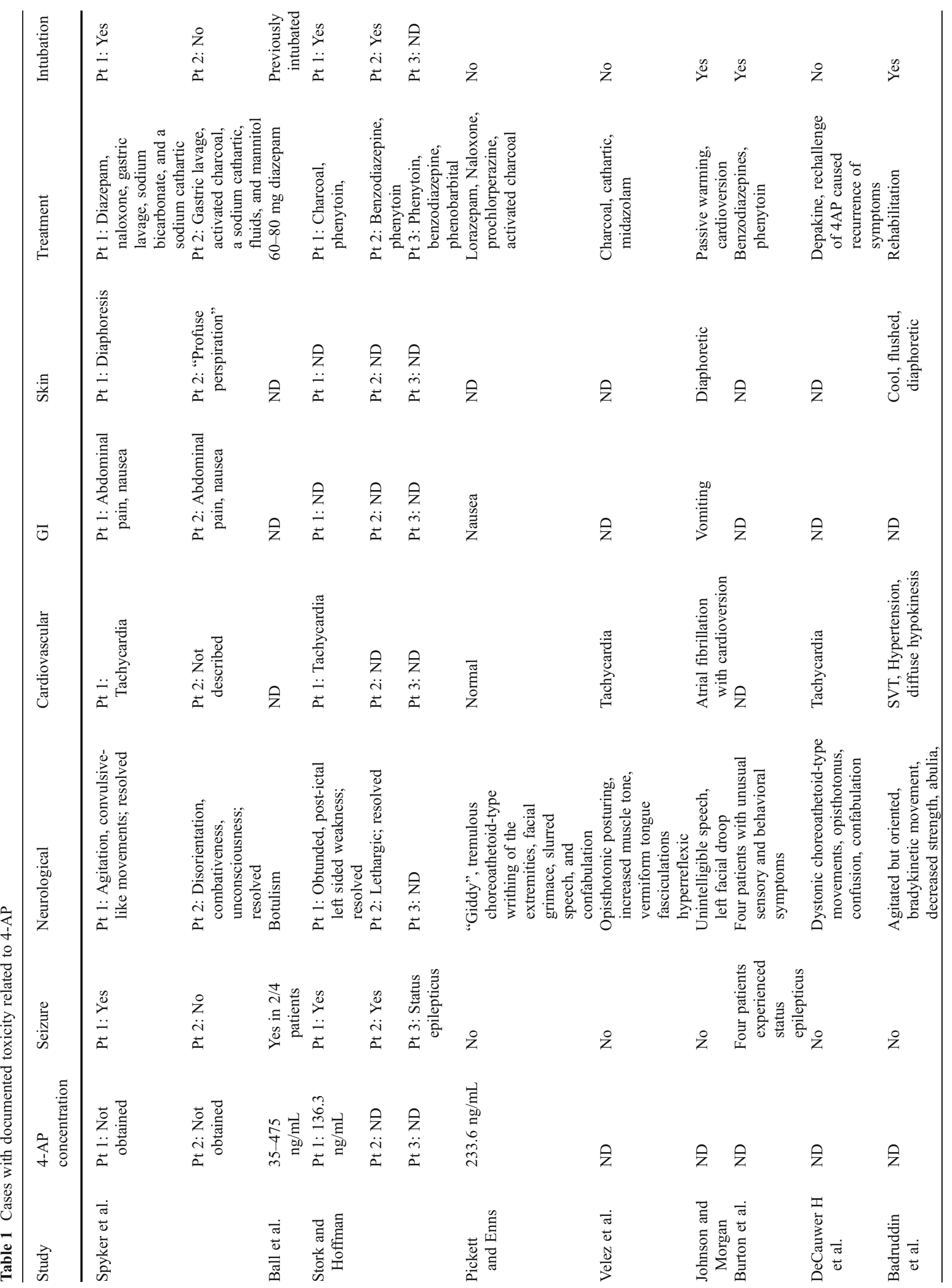




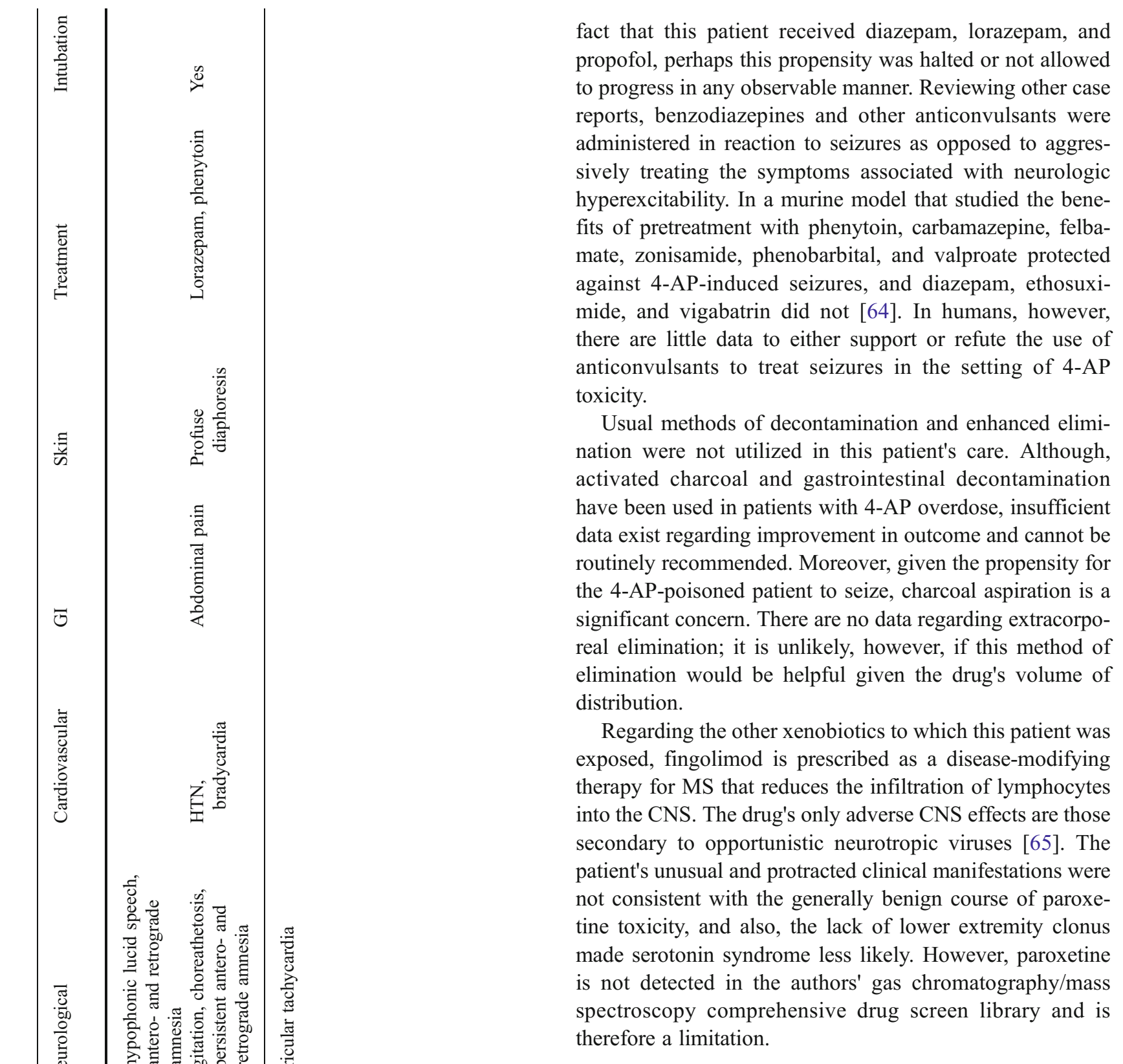

\section{Conclusion}

This case report highlights the commonalities noted in previous case reports and series including profound diaphoresis, extrapyramidal symptoms, and delirium. He was treated with aggressive administration of benzodiazepines and intubation with complete recovery. Management of patients poisoned by 4-AP centers around meticulous and aggressive supportive care with definitive airway management and controlling CNS hyperexcitability with sedatives such as benzodiazepines or similar gamma-aminobutyric acid agonist agents. Adjunctive use of dopamine antagonists for extrapyramidal effects after aggressive sedation is a treatment possibility. Insufficient data exists to routinely recommend 
phenytoin, activated charcoal, or extracorporeal elimination. Discussion with the regional poison center and medical toxicologist is recommended for all cases of 4-AP toxicity to assist in appropriate management.

\section{References}

1. Schafer EW Jr, Brunton RB, Cunningham DJ (1978) A summary of the acute toxicity of 4-aminopyridine to birds and mammals. Toxicol App Pharmacol 26:532-538

2. Bischoff K, Morgan S, Chelsvig J, Spencer D (2001) 4Aminopyridine poisoning of crows in the Chicago area. Vet Hum Toxicol 43(6):350-352

3. Buyukuysal RL, Wurtman RJ (1990) 4-Aminopyridine increases acetylcholine release without diminishing membrane phosphatidylcholine. J Neurochem 54(4):1302-1309

4. Damsma G, Biessels PT, Westerink BH et al (1988) Differential effects of 4-aminopyridine and 2,4-diaminopyridine on the in vivo release of acetylcholine and dopamine in freely moving rats measured by intrastriatal dialysis. Eur J Pharmacol 145(1):15-20

5. Jin S, Fredholm BB (1994) Role of NMDA, AMPA and kainate receptors in mediating glutamate- and 4-AP-induced dopamine and acetylcholine release from rat striatal slices. Neuropharmacology 33(9):1039-1048

6. Folgering H, Rutten J, Agoston S (1979) Stimulation of phrenic nerve activity by an acetylcholine releasing drug: 4-aminopyridine. Pfluger Arch 379:181-185

7. Vizi ES, van Dijk J, Foldes FF (1977) The effect of 4-aminopyridine on acetylcholine release. J Neural Transm 41:265-274

8. Boerma CE, Rommes JH, van Leeuwen RB, Bakker J (1995) Cardiac arrest following an iatrogenic 3,4-diaminopyridine intoxication in a patient with Lambert-Eaton myasthenic syndrome. J Toxicol Clin Toxicol 33(3):249-251

9. Maddison P, Newsom-Davis J (2005) Treatment for Lambert Eaton myasthenic syndrome. Cochrane Database Syst Rev 2:CD003279

10. Lundh H, Nilsson O, Rosén I (1979) Effects of 4-aminopyridine in myasthenia gravis. J Neurol Neurosurg Psychiatry 42(2):171-175

11. Chang FC, Bauer RM, Benton BJ et al (1996) 4-Aminopyridine antagonizes saxitoxin-and tetrodotoxin-induced cardiorespiratory depression. Toxicon 34(6):671-690

12. Ball AP, Hopkinson RB, Farrell ID et al (1979) Human botulism caused by Clostridium botulinum type E: The Birmingham outbreak. Q J Med 48:473-491

13. Simpson LL (1986) A preclinical evaluation of aminopyridines as putative therapeutic agents in the treatment of botulism. Infect Immun 52(3):858-862

14. Sherratt RM, Bostock H, Sears TA (1980) Effects of 4-aminopyridine on normal and demyelinated mammalian nerve fibres. Nature 283:570-572

15. Smith KJ, Felts PA, John GR (2000) Effects of 4- aminopyridine on demyelinated axons, synapses and muscle tension. Brain 123 (1):171-184

16. Blight AR, Toombs JP, Bauer MS, Widmer WR (1991) The effects of 4-aminopyridine on neurological deficits in chronic cases of traumatic spinal cord injury in dogs: a phase I clinical trial. J Neurotrauma 8:103-119

17. Blight AR, Gruner JA (1987) Augmentation by 4- aminopyridine of vestibulospinal free fall responses in chronic spinal-injured cats. J Neurol Sci 82:145-159

18. Grijalva I, Guízar-Sahagún G, Castañeda-Hernández G et al (2003) Efficacy and safety of 4-aminopyridine in patients with long-term spinal cord injury: a randomized, double-blind, placebo-controlled trial. Pharmacotherapy 23(7):823-834
19. Segal JL, Pathak MS, Hernandez JP et al (1999) Safety and efficacy of 4-aminopyridine in humans with spinal cord injury: long-term, controlled trial. Pharmacotherapy 19(6):713-723

20. DeForge D, Nymark J, Lemaire E et al (2004) Effect of 4aminopyridine on gait in ambulatory spinal cord injuries: a doubleblind, placebo-controlled, crossover trial. Spinal Cord 42:674-685

21. Donovan WH, Halter JA, Graves DE et al (2000) Intravenous infusion of 4-AP in chronic spinal cord injured subjects. Spinal Cord 38(1):7-15

22. van der Bruggen MA, Huisman HB, Beckerman H et al (2001) Randomized trial of 4-aminopyridine in patients with chronic incomplete spinal cord injury. J Neurol 248(8):665-671

23. Domingo A, Al-Yahya AA, Asiri Y, Eng JJ et al (2012) A systematic review of the effects of pharmacological agents on walking function in people with spinal cord injury. J Neurotrauma 29(5):865-879

24. Dunn J, Blight A (2011) Dalfampridine: a brief review of its mechanism of action and efficacy as a treatment to improve walking in patients with multiple sclerosis. Curr Med Res Opin 27 (7): $1415-1423$

25. Goodman AD, Cohen JA, Cross A et al (2007) Fampridine-SR in multiple sclerosis: a randomized, double-blind, placebo-controlled, dose-ranging study. Mult Scler 13(3):357-368

26. Uges DRA, Sohn YJ, Greijdanus B (1982) 4-Aminopyridine kinetics. Clin Pharmacol Ther 31:587-593

27. Hayes KC, Potter PJ, Hsieh JT et al (2004) Pharmacokinetics and safety of multiple oral doses of sustained-release 4-aminopyridine (Fampridine-SR) in subjects with chronic, incomplete spinal cord injury. Arch Phys Med Rehabil 85(1):29-34

28. Magdalan J (2003) New treatment methods in verapamil poisoning: experimental studies. Pol J Pharmacol 55(3):425-432

29. Agoston S, Maestrone E, van Hezik EJ et al (1984) Effective treatment of verapamil intoxication with 4-aminopyridine in the cat. J Clin Invest 73(5):1291-1296

30. Tuncok Y, Apaydin S, Gelal A et al (1998) The effects of 4aminopyridine and Bay K 8644 on verapamil-induced cardiovascular toxicity in anesthetized rats. J Toxicol Clin Toxicol 36 (4):301-307

31. Gay R, Algeo S, Lee RJ et al (1986) Treatment of verapamil toxicity in intact dogs. J Clin Invest 77(6):1805-1811

32. Graudins A, Wong KK (2010) Comparative hemodynamic effects of levosimendan alone and in conjunction with 4-aminopyridine or calcium chloride in a rodent model of severe verapamil poisoning. J Med Toxicol 6(2):85-93

33. Magdalan J, Kochman K, Antończyk A et al (2003) Successful treatment by 4 -aminopyridine of three cases of severe verapamil poisoning. Przegl Lek 60(4):271-273

34. Magdalan J, Kochman K, Smolarek M et al (2003) Severe felodipine and theophylline poisoning successfully treated by 4 -aminopyridine: a case report. Przegl Lek 60(4):268-270

35. Wilffert B, Boskma RJ, van der Voort PH et al (2007) 4Aminopyridine (fampridine) effectively treats amlodipine poisoning: a case report. J Clin Pharm Ther 32(6):655-657

36. Fiszer M, Kołaciński Z, Rechciński T (2007) The application of 4aminopyridine in calcium channel inhibitors acute poisoning. Przegl Lek 64(4-5):293-297

37. Klein L, Hopkins J (1981) Behavioral and cardiorespiratory responses to 4-aminopyridine in healthy awake horses. Am J Vet Res 42(9):1655-1657

38. Ray AC, Dwyer JN, Fambro GW, Reagor JC (1978) Clinical signs and chemical confirmation of aminopyridine poisoning in horses. Am J Vet Res 39(2):329-331

39. Spyker DA, Lynch C, Shabanowitz J, Sinn JA (1980) Poisoning with 4-aminopyridine: report of three cases. Clin Toxicol 16:487-497

40. Goodman AD, Brown TR, Cohen JA et al (2008) Dosecomparison trial of sustained-release fampridine in multiple sclerosis. Neurology 71:1134-1141 
41. Stork CM, Hoffman RS (1994) Characterization of 4-aminopyridine in overdose. J Toxicol Clin Toxicol 32:583-587

42. Pickett TA, Enns R (1996) Atypical presentation of 4-aminopyridine overdose. Ann Emerg Med 3:382-385

43. Smeets JW, Kunst MW (1995) Severe poisoning by 4aminopyridine in a body builder. Ned Tijdschr Geneeskd 139(51):2667-2669

44. Velez L, Shirazi F, Goto C et al (2003) Opisthotonic posturing with neuromuscular irritability attributable to 4-aminopyridine ingestion in a healthy pediatric patient. Pediatrics $111: \mathrm{e} 82-\mathrm{e} 84$

45. Johnson NC, Morgan MW (2006) An unusual case of 4aminopyridine toxicity. J Emerg Med 30:175-177

46. Burton JM, Bell CM, Walker SE et al (2008) 4-Aminopyridine toxicity with unintentional overdosage in four patients with multiple sclerosis. Neurology 71:1833-1834

47. De Cauwer H, De Wolf P, Couvreur F et al (2009) An unusual case of 4-aminopyridine toxicity in a multiple sclerosis patient: epileptic disorder or toxic encephalopathy? Acta Neurol Belg 109:40-41

48. Badruddin A, Menon RS, Reder AT (2009) 4-Aminopyridine toxicity mimics autoimmune-mediated limbic encephalitis. Neurology 72(12):1100-1101

49. Schwam E (2009) Severe accidental overdose of 4-aminopyridine due to a compounding pharmacy error. J Emerg Med 41(1):51-54

50. Hayes KC, Katz MA, Devane JG et al (2003) Pharmacokinetics of an immediate-release oral formulation of Fampridine (4-aminopyridine) in normal subjects and patients with spinal cord injury. J Clin Pharmacol 43(4):379-385

51. Vollmer T, Henney HR (2009) Pharmacokinetics and tolerability of single escalating doses of fampridine sustained-release tablets in patients with multiple sclerosis: a phase I-II, open-label trial. Clin Ther 31(10):2206-2214

52. Polman CH, Bertelsmann FW, van Loenen AC, Koetsier JC (1994) 4-Aminopyridine in the treatment of patients with multiple sclerosis. Long-term efficacy and safety. Arch Neurol 51(3):292-296

53. van Diemen HA, Polman CH, van Dongen TM et al (1992) The effect of 4-aminopyridine on clinical signs in multiple sclerosis: a randomized, placebo-controlled, double-blind, cross-over study. Ann Neurol 32(2):123-130
54. Korenke AR, Rivey MP, Allington DR (2008) Sustained-release fampridine for symptomatic treatment of multiple sclerosis. Ann Pharmacother 42(10):1458-1465

55. Goodman AD, Brown TR, Krupp L et al (2009) Sustained release of oral fampridine in multiple sclerosis: a randomised, doubleblind, controlled trial. Lancet 373:732-738

56. Acorda therapeutics: Data on file. Integrated Summary of Safety. Fampridine-SR in patients with Multiple Sclerosis. NDA 22-250, 2009

57. Solari A, Uitdehaag B, Guliani G et al (2003) Aminopyridines for symptomatic treatment in multiple sclerosis. Cochrane Database Syst Rev 2:CD001330

58. Kelley BJ, Rodriguez M (2009) Seizures in patients with multiple sclerosis: epidemiology, pathophysiology and management. CNS Drugs 23:805-815

59. Bever CT Jr, Young D, Anderson PA et al (1994) The effects of 4aminopyridine in multiple sclerosis patients: results of a randomized, placebo-controlled, double-blind, concentration-controlled, crossover trial. Neurology 44(6):1054-1059

60. Van Diemen HA, Polman CH, Koetsier JC et al (1993) 4Aminopyridine in patients with multiple sclerosis: dosage and serum level related to efficacy and safety. Clin Neuropharmacol 16(3):195-204

61. Renganathan M, Sidach S, Blight AR (2009) Effects of 4Aminopyridine on Cloned hERG Channels Expressed in Mammalian Cells. Arch Drug Inf 2(3):51-57

62. March B, Cardi T (2009) Assessment of the cardiac safety of fampridine-SR sustained-release tablets in a thorough QT/QTc evaluation at therapeutic and supratherapeutic doses in healthy individuals. Expert Opin Investig Drugs 18:1807-1815

63. Isoda WC, Segal JL (2003) Effects of 4-aminopyridine on cardiac repolarization, PR interval, and heart rate in patients with spinal cord injury. Pharmacotherapy 23:133-136

64. Yamaguchi S, Rogawski MA (1992) Effects of anticonvulsant drugs on 4-aminopyridine-induced seizures in mice. Epilepsy Res 11:9-16

65. Scott LJ (2011) Fingolimod: a review of its use in the management of relapsing-remitting multiple sclerosis. CNS Drugs 25(8):673-698 